\title{
Storage stability of freeze-dried Lactobacillus plantarum S20 starter culture as affected by various formulations of drying medium, and its fermentation characteristics in mung bean (Vigna radiata $\mathrm{L}$.) slurry
}

\author{
*Sulabo, A.S.L., Villasanta, M.E.L., Hermo, K.G., Lascano, R.A., Collado, L.S. and \\ Babaran, G.M.O.
}

Julian A. Banzon Hall, Institute of Food Science and Technology, College of Agriculture and Food Science, University of the Philippines Los Baños, Laguna, Philippines, 4031

\section{Article history:}

Received: 6 November 2019

Received in revised form: 6

February 2020

Accepted: 9 February 2020

Available Online: 28

February 2020

\section{Keywords:}

Lactobacillus plantarum,

Freeze drying,

Mung bean,

Trehalose,

Sucrose

DOI:

https://doi.org/10.26656/fr.2017.4(4).361

\begin{abstract}
Development of an active starter culture is essential in the production of safe and highquality fermented foods. Freeze-drying is an effective microbial cell immobilization technology intended to produce active and stable starter cultures for long-term storage. To determine the influence of various drying medium formulations with mung bean powder and disaccharides on the viability of $L$. plantarum S20 during freeze-drying and subsequent storage at $6 \pm 2{ }^{\circ} \mathrm{C}$ and $30 \pm 1{ }^{\circ} \mathrm{C}$, three treatments of drying medium consisting of mung bean powder without disaccharides (MBP), MBP with 5\% (w/v) trehalose $(\mathrm{MBP}+\mathrm{T})$, and MBP with 5\% (w/v) sucrose (MBP+T) were evaluated. Results showed that $L$. plantarum S20 viability after freeze-drying ranged from 9.56 to $10.03 \log (\mathrm{CFU} / \mathrm{g})$ with viability loss ranging from 0.20 to $0.51 \log (\mathrm{CFU} / \mathrm{g})$, with $\mathrm{MBP}$ being the least effective $(p<0.05)$ in minimizing viability loss. Supplementing MBP with either 5\% sucrose or $5 \%$ trehalose improved $(p<0.05)$ survival of freeze-dried L. plantarum S20; and both disaccharides exhibit similar $(p>0.05)$ cryoprotective effects on L. plantarum S20 during freeze-drying and subsequent storage. Storage at $6 \pm 2^{\circ} \mathrm{C}$ for 180 days resulted in significant decreases of 2.15, 2.17, and $3.27 \log (\mathrm{CFU} / \mathrm{g})$ in L. plantarum $\mathrm{S} 20$ population in $\mathrm{MBP}+\mathrm{T}, \mathrm{MBP}+\mathrm{S}$, and MBP, respectively. A more drastic decline $[>6.0 \mathrm{Log}(\mathrm{CFU} / \mathrm{g})]$ in L. plantarum S20 population was observed in freeze-dried culture stored at $30 \pm 1^{\circ} \mathrm{C}$ for 60 days. Fermentation characteristics of freeze-dried L. plantarum S20 in mung bean slurry were also determined. Freeze-dried L. plantarum S20 in MBP with 5\% (w/v) sucrose was able to acidify mung bean slurry from $\mathrm{pH} 6.8$ to $\mathrm{pH} 3.8$ after 8 hrs with maximum LAB population of $9.2 \log (\mathrm{CFU} / \mathrm{mL})$. Acidification of mung bean slurry by fresh culture (non-freeze-dried) on the other hand was relatively slower where $\mathrm{pH}$ dropped from 6.8 to $\mathrm{pH} 3.72$ after $24 \mathrm{hrs}$. Current work suggested that lyophilized L. plantarum S20 could be used as a starter culture for mung bean-based fermentations but further research on this area is needed.
\end{abstract}

\section{Introduction}

Fermentation is an old but useful form of food preservation, and it is valuable in developing functional foods. It is commonly used in food processing to enhance the safety, nutritional content, flavor, and texture of food. The most popular fermented foods are those achieved by lactic acid bacteria (LAB) (Rezac et al., 2018), which is a diverse group of Gram-positive bacteria capable of converting carbohydrates into lactic acid as the major end product (Paul et al., 2017). A variety of $\mathrm{LAB}$ species, particularly those that belong in the genus Lactobacillus, can be found in a variety of fresh produce, fermented foods, and mammalian digestive tracts. The species Lactobacillus plantarum is the most studied Lactobacillus due to its ability to thrive in a wide range of environmental niches. Different strains of $L$. plantarum have emerged as functional LAB exhibiting a long history of safe use. It is considered as "generally recognized as safe" (GRAS) and has qualified presumption of safety (Ray and Joshi, 2014; Ricci et al., 2017). The versatility of $L$. plantarum makes it a good functional organism to be used in a wide range of applications in the food industry, especially as a starter culture. 
The use of starter cultures plays an essential role in controlled fermentations to ensure the safety and quality of commercially produced fermented foods. A starter culture is composed of either a single species or a mixture of microorganisms that are added directly into a food matrix to start the fermentation process, and to obtain a desired and consistent quality of the finished product (Durso and Hutkins, 2003). The production of starter cultures aims to ensure long-term delivery of viable and stable cultures, which can be achieved through the application of preservation technologies (Carvalho, 2003a). Freeze-drying is a cell immobilization technology that can be used to preserve active and stable starter cultures. It has been established in the food industry as the best method of preserving bacterial cultures in a powdered/crystalline form for long -term storage. However, freeze-drying can result in cell injury that could lead to cell death. Thus, selecting appropriate drying medium as a protective matrix can produce a stable final formulation of freeze-dried cell culture with minimal viability loss. Several studies have investigated the use of various protective agents during feeze-drying consisting of additives (Carvalho et al., 2002), disaccharides, and skim milk (Carvalho et al., 2003b; Jalali et al., 2012; Mendoza et al., 2013; Gisela et al., 2014; Jofré et al., 2015) in order to minimize viability loss of $\mathrm{LAB}$ during cryopreservation. In addition, drying media also serve as carriers of freezedried starter cultures for fermentation applications. The use of skim milk supplemented with disaccharides as drying medium for dairy starter cultures has been successful in minimizing bacterial cell death during freeze-drying and subsequent storage (Carvalho et al., 2004). Food-grade plant-based materials were also utilized as components of freeze-drying media for probiotic bacteria and non-dairy starter cultures and have shown to reduce microbial viability loss. A number of these plant-based materials include plant protein powder (Savedboworn et al., 2017), fruit powders (Trachoo et al., 2008; Nualkaekul et al., 2012), soybean flour (Trachoo et al., 2008), plant extracts and fibers (Hongpattarakere et al., 2012). Starchy materials like flours of rice, cassava, yam, millet, maize, and sorghum have been utilized as cryoprotective drying media for non-dairy starter cultures for gari and beer fermentations (Okafor et al., 1999; N'Guessan et al., 2016). Mahidsanan et al. (2017) also reported that a novel soybean flour as an inexpensive cryoprotectant option showed enhanced protection on Bacillus subtilis SBMYP-1 starter culture for Thu-nao (fermented soybean) processing.

Mung bean (Vigna radiata L.) or munggo, locally known in the Philippines, is a pulse crop with high protein content (21-31\%) and considered as a poor man's meat (Anwar et al., 2007). Mung bean is also known for its high carbohydrates content (64.2\%) with small portions of dietary fiber $(14.6 \%)$, ash $(3.9 \%)$ and some traces of vitamins and minerals (BAFS, 2012). In food processing applications, mung bean has established its popularity due to its good quality starch, which comprises a majority of total carbohydrates. Starch in mung bean comprises more than $50 \%$ of the total seed weight (Li et al., 2011). It has the excellent gelling capability, pasting property, and cohesiveness, becoming it a better choice for film-forming biopolymers and starch noodles (Kim et al., 2007; Li et al., 2015; Rompothi et al., 2017). Fermentation of mung bean with $L$. plantarum strains was associated with the release of angiotensin I-converting enzyme (ACE) inhibitory peptides, which are drugs used to lower blood pressure. Fermentation of pea with L. plantarum 299 has produced bioactive metabolites that facilitated the release of angiotensin I-converting enzyme (ACE) inhibitory peptides during in vitro gastrointestinal process (Torino et al., 2013). L. plantarum B1-6-fermented mung bean milk was shown to produce significantly higher ACE inhibitory activity $(67.5 \%)$ at the end of fermentation (Wu et al., 2015). In addition, Wu et al. (2015) also demonstrated that mung bean milk could be a carrier matrix of probiotics. Thus, it is interesting to explore the potential of utilizing of mung bean as starter culture drying medium and fermentation substrate for $L$. plantarum.

Freeze-drying at commercial scale is an expensive dehydration technology. However, it is still the most used method at commercial scale for the production of starter cultures. Thus, utilizing freeze-drying media formulated with low-cost ingredients like mung bean should be able to reduce a portion of the cost. To date, no studies have been conducted in utilizing mung bean as a drying medium component that will also serve as a carrier matrix for $L$. plantarum starter culture. This study aimed to evaluate the influence of various protective agents formulated with mung bean powder and disaccharides on the freeze- and post-freeze-drying survival of L. plantarum S20 starter, which can be used in mung bean-based fermentation. Results of the study will provide baseline data necessary to produce starter culture by utilizing cheap food-grade materials like mung bean as a component of drying medium for the production of novel functional non-dairy fermented foods.

\section{Materials and methods}

\subsection{Preparation of starter culture}

\subsubsection{Cultivation of Lactobacillus plantarum S20}

Lactobacillus plantarum S20 was acquired from the 
Philippine National Collection of Microorganisms of the University of the Philippines Los Baños College, Laguna. It was isolated from Nem chua, a fermented meat product of Vietnam with $98 \%$ homology with $L$. plantarum WCFS1 (Nguyen et al., 2010). It was isolated using streak plating technique and identified by its $16 \mathrm{~s}$ rDNA sequence. L. plantarum S20 was maintained in 7.0 $\mathrm{mL}$ deMann Rogosa Sharpe (MRS) broth (HiMedia, Mumbai, India) at $4 \pm 1^{\circ} \mathrm{C}$ and sub-cultured every 2 weeks.

\subsubsection{Preparation of mung bean powder}

Whole green mung bean seeds (NSIC MG-14) were purchased from the Bureau of Plant Industries-National Crop Research and Development Center of Los Baños, Laguna. The seeds are characterized to be dull-green and can be planted and harvested during the wet and dry season. Seeds were dried at $70^{\circ} \mathrm{C}$ for $2 \mathrm{hrs}$ (moisture content $=9.33 \pm 0.40 \%$ ) and were then pulverized with the fabricated stainless steel pin mill machine $(50 \mathrm{Kg}$ capacity; Alameda, Tondo, Manila, Philippines) and screened through 80-mesh sieve. Mung bean powder was then packed and vacuum-sealed in Polyethylene bags and stored at room temperature until use.

\subsubsection{Preparation of drying medium}

A total of three treatments of drying medium formulated with mung bean base mixture and two types of disaccharides (sucrose and trehalose) were prepared. The treatments include mung bean with $5 \%(\mathrm{w} / \mathrm{v})$ trehalose $(\mathrm{MBP}+\mathrm{T})$, mung bean with $5 \%(\mathrm{w} / \mathrm{v})$ sucrose $(\mathrm{MBP}+\mathrm{S})$, and mung bean powder only (MBP). A mixture of mung bean powder and sterile $0.85 \%(\mathrm{w} / \mathrm{v})$ $\mathrm{NaCl}$ solution was used as base mixture ingredients of the freeze-drying medium. The proportion used in preparing the base mixture of drying medium was based on the optimized cryoprotectant formulation using skim milk described by Gisela et al. (2014) with some modifications. About $25 \mathrm{~g}$ of mung bean powder was diluted with $0.85 \%$ (w/v) $\mathrm{NaCl}$ solution to $100 \mathrm{~mL}$. The mixture was then transferred to a sterile media bottle and pasteurized at $71 \pm 1^{\circ} \mathrm{C}$ for $66 \pm 1$ mins in order to inactivate pathogenic bacteria and reduce population spoilage microorganisms. The hot mixture was then assigned to one of the three treatments: MBP, MBP $+\mathrm{T}$, and $\mathrm{MBP}+\mathrm{S}$. Hot mixture assigned to MBP with disaccharides was prepared by supplementing it with either trehalose (Hayashibara, Japan) or sucrose (AjaxFineChem Univar, Australia) at 5\% (w/v) inclusion rate. All treatments were then allowed to cool down at room temperature.

\subsubsection{Preparation culture}

The preparation of starter culture was based on the procedures described by Yao et al. (2009) with major modifications. About $1 \mathrm{~mL}$ of overnight (16-18 hrs at $37^{\circ} \mathrm{C}$ ) MRS-cultured L. plantarum S20 was propagated in fresh $100 \mathrm{~mL}$ MRS broth at $37^{\circ} \mathrm{C}$ for $18 \mathrm{hrs}$. The $L$. plantarum S20 cells were then harvested by centrifugation at $4300 \mathrm{x} g$ at $4^{\circ} \mathrm{C}$ for 15 mins and washed with sterile $0.85 \% \mathrm{NaCl}$ solution twice. Washed cells were then re-suspended in $5 \mathrm{~mL}$ of sterile $0.85 \% \mathrm{NaCl}$ solution. The resulting cell suspension was then aseptically transferred onto a media bottle containing one of the previously prepared freeze-drying media. All mixtures were then aseptically transferred onto sterile petri dishes and were immediately frozen for $24 \mathrm{hrs}$ at $20^{\circ} \mathrm{C}$. All treatments were then lyophilized at a vacuum pressure of 0.20 Torr (ULVAC DF-01H, ULVAC Corp.), and secondary drying temperature set at $40^{\circ} \mathrm{C}$ for $72 \mathrm{hrs}$. Preparing a freeze-drying medium devoid of any of the cryoprotectants and L. plantarum S20 was used as a negative control.

\subsubsection{Packaging and storage of freeze-dried starter culture}

Under a sterile laminar flow cabinet, freeze-dried cultures were pulverized aseptically using a sterile spatula and transferred onto pre-sterilized amber glass vials. Sample vials were immediately sealed with sterile rubber stopper and stored either at $6 \pm 2{ }^{\circ} \mathrm{C}$ for 180 days in the chiller or at $30 \pm^{\circ} \mathrm{C}$ for 60 days in the incubator.

\subsection{Evaluation of fermentation performance of the starter culture on mung bean slurry}

\subsubsection{The mung bean slurry preparation}

Whole green mung bean seeds (NSIC MG-14) were soaked in water for 9-10 hrs. Soaked beans were manually de-hulled and a 200 g portion was transferred onto a clean stainless steel stockpot. About $1.5 \mathrm{~L}$ of sterile distilled water was added into the beans and the mixture was heated to boiling at approx. $100^{\circ} \mathrm{C}$. Immediately after boiling, the heat was adjusted to the medium low setting and the mixture was heated to approx. $100^{\circ} \mathrm{C}$ for another 20 mins or until beans become soft. The mung bean mixture was then transferred into a blender and an additional $500 \mathrm{~mL}$ of sterile distilled water was used to wash the remaining mixture. The mixture was then homogenized for 2 mins and transferred into a clean stainless stockpot. The mixture was then added with $500 \mathrm{~mL}$ sterile distilled water and was brought to boil. About $250 \mathrm{~mL}$ portion of mung bean slurry was immediately transferred into a 
sterile screw-capped media bottle glass container and was supplemented with sucrose at $5 \%(\mathrm{w} / \mathrm{v})$ inclusion rate. The mixture was then transferred to the boiling water bath and was allowed to be pasteurized at $71 \pm 1{ }^{\circ} \mathrm{C}$ for 66 mins and was allowed to cool at room temperature.

\subsubsection{Fermentation of mung bean slurring using} freeze-dried Lactobacillus plantarum S20 culture

Three fermentation treatments containing $250 \mathrm{~mL}$ mung bean slurry were prepared for fermentation experiment. The first treatment of mung bean slurry was supplemented with fresh L. plantarum S20 culture. This was done by harvesting $L$. plantarum S20 cells from 10 $\mathrm{mL}$ overnight $\left(37^{\circ} \mathrm{C}\right.$ for $\left.18 \mathrm{hrs}\right)$ culture of $L$. plantarum S20 in MRS broth, using the procedure described in the preparation of starter culture for freeze-drying (Section 2.1.4). Harvested cells from $10 \mathrm{~mL}$ of overnight culture (approx. $10^{10} \mathrm{CFU} / \mathrm{mL}$ ) in MRS broth were re-suspended in $9 \mathrm{~mL} 0.85 \% \mathrm{NaCl}$. About $5 \mathrm{~mL}$ of the cell suspension was added to previously prepared mung bean slurry to contain initial LAB population of $7 \log (\mathrm{CFU} / \mathrm{mL})$. The second fermentation treatment of mung bean slurry was supplemented with freeze-dried $L$. plantarum S20 culture. This was done by rehydrating $1 \mathrm{~g}$ of 2-day chilled freeze-dried L. plantarum S20 culture (approx. $10^{10} \mathrm{CFU} / \mathrm{g}$ ) in $9 \mathrm{~mL} 0.85 \% \mathrm{NaCl}$ solution for $15 \mathrm{~min}$. About $5 \mathrm{~mL}$ of the rehydrated cells were transferred onto $250 \mathrm{~mL}$ pasteurized mung bean slurry to contain initial LAB population of $7 \log (\mathrm{CFU} / \mathrm{mL})$. Lastly, the third fermentation treatment of mung bean slurry was not supplemented with L. plantarum S20 culture and served as the control of the experiment.

\subsubsection{Sample collection from the fermentation mixture}

During fermentation, sample aliquots for LAB viability test, $\mathrm{pH}$, and total soluble solids (TSS) measurements were aseptically drawn from the fermenting mung bean slurry at $0,4,8,16,24$, and $32 \mathrm{~h}$ of fermentation at $37^{\circ} \mathrm{C}$.

\subsection{Analytical procedures and $L A B$ viability test}

\subsubsection{Freeze-drying and storage viability L.actobacillus plantarum 520}

The ability of $L$. plantarum S20 to survive freezedrying and storage conditions in mung bean powder with either trehalose or sucrose was determined using standard spread plating technique. To determine the influence of cryoprotectants on L. plantarum S20 viability in mung bean powder during freeze-drying, about $1 \mathrm{~g}$ of freeze-dried culture was aseptically drawn from each freeze-drying medium treatment before and after the freeze-drying process. To assess the stability of freeze-dried L. plantarum S20 during storage, the same amount of freeze-dried culture was aseptically drawn at $0,60,120$, and 180 days of $6 \pm 2{ }^{\circ} \mathrm{C}$ storage and at 0,20 , 40 , and 60 days of $30 \pm 1{ }^{\circ} \mathrm{C}$ storage. Each sample obtained was serially diluted in $0.1 \%$ peptone (HiMedia $\mathrm{Sa}$, Mumbai, India). About $0.1 \mathrm{~mL}$ sample aliquot from the diluted sample was spread plated onto MRS agar and overlaid with $5.0 \mathrm{~mL}$ molten MRS agar. Plates were then incubated at $37^{\circ} \mathrm{C}$ for $48 \mathrm{hrs}$. Viable cell count was reported as $\log (\mathrm{CFU} / \mathrm{g})$.

\subsubsection{Enumeration of $L A B$ population during fermentation}

Population of lactic acid bacteria during fermentation of mung bean slurry with L. plantarum S20 was enumerated using a standard pour plating technique on MRS agar. About $1 \mathrm{~mL}$ sample aliquot drawn from fermenting mung bean slurry (section 2.2.3) was serially diluted in $0.1 \%$ peptone. About $1 \mathrm{~mL}$ of the diluted sample was pour plated with molten MRS agar. Plates were then incubated at $37^{\circ} \mathrm{C}$ for $48 \mathrm{hrs}$. Viable LAB counts were reported as $\log \mathrm{CFU} / \mathrm{mL}$.

\subsubsection{Water activity of freeze-dried starter during storage}

About $2 \mathrm{~g}$ of sample was obtained from freeze-dried L. plantarum S20 before and after 180 and $60 \mathrm{~d}$ storage at $6 \pm 2{ }^{\circ} \mathrm{C}$ and $30 \pm 1{ }^{\circ} \mathrm{C}$, respectively. Water activities of freeze-dried samples were then measured using a water activity meter (LabSwift- $\mathrm{a}_{\mathrm{w}}$ meter; Novasina, Hamilton, NJ, USA) at room temperature.

\subsubsection{Total soluble solids and $p H$ during mung bean slurry fermentation}

About $20 \mathrm{~mL}$ of sample was used for TSS and $\mathrm{pH}$ measurement. The total soluble solids content of samples was measured using a handheld refractometer (Atago, Japan) and the results were expressed as ${ }^{\circ}$ Brix. The $\mathrm{pH}$ of samples was measured using a hand-held $\mathrm{pH}$ meter fitted with spear-shaped probe (PH60S; Apera Instruments) calibrated with $\mathrm{pH} 7.00$ and $\mathrm{pH} 4.00$ buffer solution. All readings for each parameter were done in duplicate for each sample.

\subsection{Statistical analysis}

Analysis of variance (ANOVA) with repeated measures was used to determine treatments significantly differ from each other, using 5\% level of significance. A pairwise comparison using Tukey's HSD (honestly significant difference) was used to compare means using $5 \%$ level of significance. The analysis was carried out using SPSS Statistics (Version 25; IBM, USA). Both freeze-drying and storage stability experiments were 
independently replicated three times with two independent samples used in each replication. Fermentation experiment, on the other hand, was replicated four times with one independent sample used in each replication.

\section{Results and discussion}

\subsection{Effect of protective agents on Lactobacillus} plantarum S20 during freeze-drying

The population $L$. plantarum S20 in mung bean powder with or without cryoprotectants after freezedrying is shown in Figure 1. It is shown that viability after freeze-drying ranged from 9.56 to $10.03 \log$ (CFU/ g) with viability loss ranging from 0.20 to $0.51 \mathrm{log}$ (CFU/g). Addition of either sucrose or trehalose at $5 \%$ $(\mathrm{wt} / \mathrm{v})$ exhibit improved protection on L. plantarum S20 during freeze-drying where higher $(p<0.05)$ level of surviving $L$. plantarum population remained after freezedrying was observed.

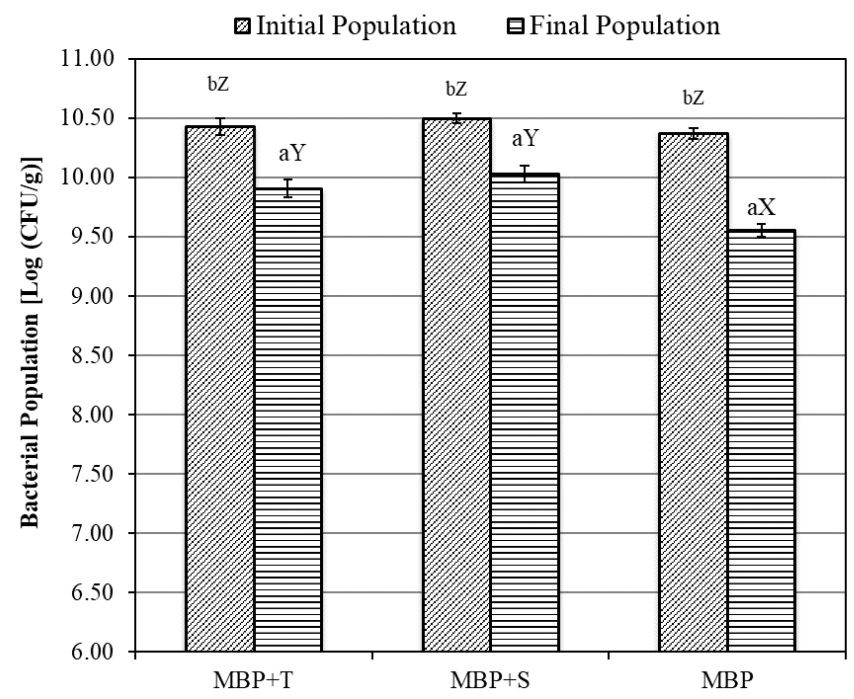

Figure 1. Population of L. plantarum S20 in various freezedrying media before and after lyophilization. Data presented as mean $\log (\mathrm{CFU} / \mathrm{g})$ from 6 independent samples. Drying medium treatments: $\mathrm{MBP}+\mathrm{T}=$ mung bean powder with $5 \%$ trehalose; $\mathrm{MBP}+\mathrm{S}=$ mung bean powder with $5 \%$ sucrose; $\mathrm{MBC}=$ mung bean powder only. ${ }^{\mathrm{ab}}$ Values within each treatment not sharing the same letters are different from each other $(p<0.05)$ analyzed using Tukey's HSD post hoc test; ${ }^{\mathrm{XYZ}}$ Values across treatments not sharing the same letters are different from each other $(p<0.05)$ analyzed using Tukey's HSD post hoc test; Error bars represent standard error of the mean.

Viability loss observed in the current study was expected due to cell injury caused by the freezing and dehydration process. Several studies reported that cellular damage during freeze-drying was largely associated with cell membrane damage due to ice crystal formation that leads to high osmolarity of the cell (Telang et al., 2003), macromolecule denaturation
(Thammavongs et al., 1996), and the removal of water (Allison et al., 1999; De Paz et al., 2002). Viability loss in L. plantarum S20 population observed in this study was almost similar to the values reported by Hongpattarakere et al. (2012). They reported that freezedrying of $L$. plantarum suspended in MRS growth medium added with and without mung bean fiber has resulted in 0.25 and $0.51 \log (\mathrm{CFU} / \mathrm{g})$ viability loss. In the present work, all treatments were exposed at $-20^{\circ} \mathrm{C}$ for $24 \mathrm{hrs}$ freezing temperature prior to freeze-drying. This freezing temperature may have resulted in bigger ice crystals that resulted in cell injury. Hongpattarakere et al. (2012) and Perry (1998) noted that slow freezing occurring at temperatures above $-30^{\circ} \mathrm{C}$ may result in poor survival due to loss of water from the cell while increasing the effects of solute concentration. Exposure of $L$. plantarum culture to extremely low freezing temperature of $-196^{\circ} \mathrm{C}$ have shown to have the significantly lower freeze-drying viability loss of 0.18 $\log (\mathrm{CFU} / \mathrm{g})$ as compared to -80 and $-20^{\circ} \mathrm{C}$ with cell reduction of 0.57 and $0.38 \log (\mathrm{CFU} / \mathrm{g})$, respectively (Hongpattarakere et al., 2012).

Current results showed that using mung bean powder only as drying medium exhibit significantly lower viability compared to those formulated with either sucrose or trehalose. The surviving L. plantarum S20 in mung bean drying medium after freeze-drying was 9.56 $\log (\mathrm{CFU} / \mathrm{g})$. This survival level is equivalent to approx. $31 \%$ of the initial population level before freeze-drying. This survival rate was slightly better compared to the survival rate $(23 \%)$ of L. plantarum TISTR 2075 when $15 \%$ plant protein was used as a protective and drying medium (Savedboworn et al., 2017). In the current study, the use of ground mung bean may have served as inert bulking agent forming viscous layer that provided some protection on L. plantarum S20 cells during the freezedrying process. Carvalho et al. (2004) noted that some high molecular weight substances present in the drying medium like polysaccharides and proteins have no capability to penetrate the cell wall or interact with the cell wall or membrane. Their protective effect lies on their ability to be adsorbed on the surfaces of microorganisms forming viscous layer, which could cause partial removal of water from the cell to the surroundings. This would inhibit ice crystal growth while keeping the structure of amorphous ice in the close proximity of the cell (Hubálek, 1996). Consequently, this will decrease the amount of ice crystals inside the cell, hence could prevent cell death.

The addition of either trehalose or sucrose at $5 \%(\mathrm{w} /$ v) in the current study appeared to have increased the resistance of $L$. plantarum S20 to freeze-drying. Previous studies showed that these two disaccharides were 
effective as protective agents for cryopreservation of lactic acid bacteria (Chavarri et al., 1988; Carvalho et al., 2002; Carvalho et al., 2003b; Gisela et al., 2014). Cryoprotectants in freeze-drying serve as antifreeze agents, which minimize cell death by lowering the melting point of freeze-drying media (Polge et al., 1949). This would eventually freeze the medium surrounding the cell faster than the intracellular components, hence, preventing cell death. Carvalho et al. (2004) noted that trehalose and sucrose have the ability to decrease the transition temperature of dry membranes by replacing water between the lipid head groups. This phenomenon prevents phase transition, and its accompanying leakage upon rehydration (Leslie et al., 1995; Castro et al., 1997). An earlier study on cryopreservation of biomaterials suggested that trehalose was more effective cryoprotectant than other sugars (Crowe et al., 1996). On the contrary, current work did not observe a significant difference between the cryoprotective ability of sucrose and trehalose. Current observation is supported by a previous study conducted by Strasser et al. (2009) where trehalose and sucrose demonstrated similar cryoprotective effects on $L$. plantarum strain IFA No. 278 during freeze-drying. In addition, Strasser et al. (2009) also reported that these two cryoprotectants were the most effective among the cryoprotectants tested in enhancing the survival of $L$. plantarum strain IFA No. 278 during lyophilization.

\subsection{Stability of lyophilized Lactobacillus plantarum S20 during storage}

Post-freeze-drying survival of L. plantarum S20 during chilled and ambient temperature storage is shown in Figure 2. It is shown that storage of freeze-dried cultures for either 180 days at $6 \pm 2^{\circ} \mathrm{C}$ or 60 days at $30 \pm 1^{\circ}$ $\mathrm{C}$ resulted in a significant decrease on the viability of lyophilized $L$. plantarum S20 cells. At the end of $180 \mathrm{~d}$

chilled storage period, viable $L$. plantarum population in $\mathrm{MBP}+\mathrm{T}, \mathrm{MBP}+\mathrm{S}$, and MBP decreased $(p<0.05)$ by 2.15 , 2.17, and $3.27 \log (\mathrm{CFU} / \mathrm{g})$, respectively (Figure 2A). Meanwhile, L. plantarum S20 did survive poorly during storage at a much higher temperature (Figure 2B). Ambient storage for $60 \mathrm{~d}$ resulted in $>4 \log \mathrm{CFU} / \mathrm{g}$ decrease in viability of $L$. plantarum S20. Results also show that for both storage temperatures, the addition of either 5\% sucrose or 5\% trehalose did improve survival of L. plantarum S20 during storage with lower population reduction as compared to drying medium containing ground mung bean only. No difference $(p>0.05)$ in viability was observed in L. plantarum S20 population in $\mathrm{MBP}+\mathrm{T}$ and $\mathrm{MBP}+\mathrm{S}$ during ambient and chilled storage indicating that both cryoprotectants have similar protective effects on L. plantarum S20 survival at post-freeze-drying conditions. In addition, MBP exhibit lowest $(p<0.05)$ survival after $180 \mathrm{~d}$ (cell reduction 3.78 $\log \mathrm{CFU} / \mathrm{g}$ ) and 60 days (5.48 log CFU/g) storage at chilled and ambient storage, respectively. It appears that storage of freeze-dried cultures with mung bean powder and cryoprotectants at $6 \pm 2^{\circ} \mathrm{C}$ for 60 and $120 \mathrm{~d}$ manage to preserve L. plantarum S20 survival $>8.0 \mathrm{Log}(\mathrm{CFU} / \mathrm{g})$ with only $\leq 0.70$ and $\leq 1.70 \log (\mathrm{CFU} / \mathrm{g})$ reduction in cell population, respectively.

The drastic decline in L. plantarum S20 population during chilled and ambient storage could be attributed to relatively high water activities of the freeze-dried samples. Table 1 shows the water activity values of freeze-dried L. plantarum S20 in ground mung bean using different cryoprotectants before and after 180 and $60 \mathrm{~d}$ of storage at $6 \pm 2{ }^{\circ} \mathrm{C}$ and $30 \pm 1{ }^{\circ} \mathrm{C}$, respectively. It is also shown that water activities slightly increase $(p<0.05)$ after storage at $6 \pm 2^{\circ} \mathrm{C}$ and $30 \pm 1^{\circ} \mathrm{C}$. Generally, dehydrated microorganisms survive better at much lower water activity. Stability of dried LAB upon storage is

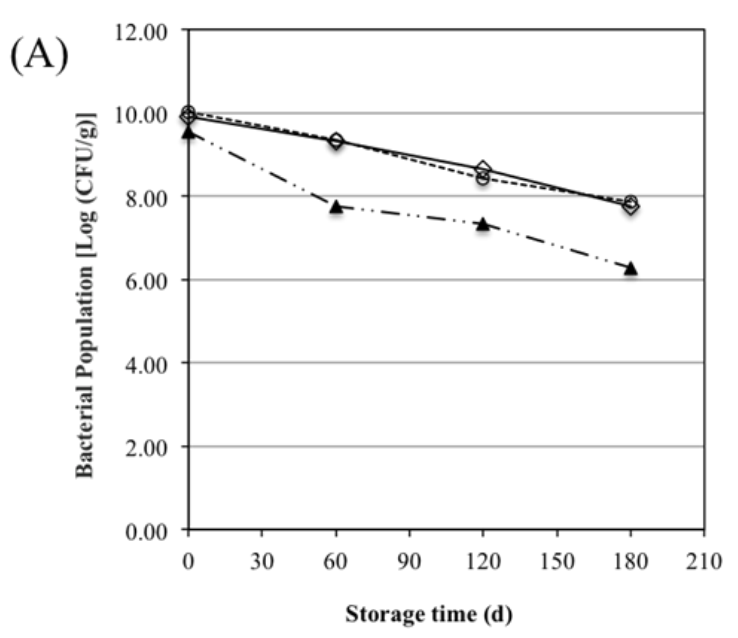

(B)

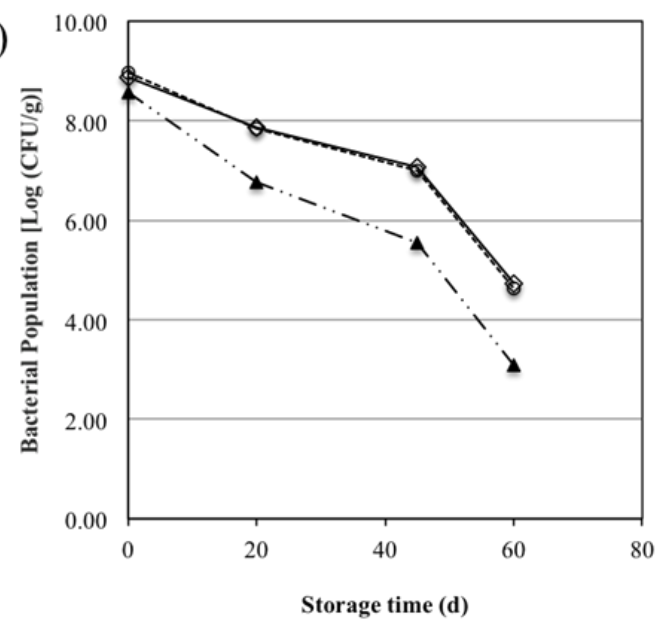

Figure 2. Population of lyophilized L. plantarum S20 culture in various freeze-drying media during storage at $6 \pm 2^{\circ} \mathrm{C}$ for 180 days (A) and at $30 \pm 1{ }^{\circ} \mathrm{C}$ for 30 (B). Data presented as mean $\log (\mathrm{CFU} / \mathrm{g})$ from 6 independent samples. Drying medium treatments: Open diamond $=\mathrm{MBP}+\mathrm{T}$ (mung bean powder with $5 \%$ trehalose); Open circle $=\mathrm{MBP}+\mathrm{S}$ (mung bean powder with $5 \%$ sucrose); Closed triangle with dash line = MBP (mung bean powder only). 
Table 1. Water activity of freeze-dried cultures throughout storage at $6 \pm 2^{\circ} \mathrm{C}$ for 180 days and at $30 \pm 1{ }^{\circ} \mathrm{C}$ for 60 days.

\begin{tabular}{lcccc}
\hline \multirow{2}{*}{\multicolumn{1}{c}{ Drying medium }} & \multicolumn{2}{c}{ Chilled storage $\left(6 \pm 2^{\circ} \mathrm{C}\right)$} & \multicolumn{2}{c}{ Ambient storage $\left(30 \pm 1^{\circ} \mathrm{C}\right)$} \\
\cline { 2 - 5 } & 0 days & 180 days & 0 days & 60 days \\
\hline Mung bean with 5\% (w/v) trehalose & $0.409 \pm 0.013^{\mathrm{aX}}$ & $0.458 \pm 0.008^{\mathrm{aY}}$ & $0.413 \pm 0.238^{\mathrm{aX}}$ & $0.438 \pm 0.253^{\mathrm{aY}}$ \\
Mung bean with 5\% (w/v) sucrose & $0.396 \pm 0.010^{\mathrm{aX}}$ & $0.461 \pm 0.004^{\mathrm{aY}}$ & $0.401 \pm 0.231^{\mathrm{aX}}$ & $0.421 \pm 0.243^{\mathrm{aY}}$ \\
Mung bean & $0.429 \pm 0.009^{\mathrm{aX}}$ & $0.472 \pm 0.006^{\mathrm{aY}}$ & $0.412 \pm 0.238^{\mathrm{aX}}$ & $0.441 \pm 0.255^{\mathrm{aY}}$ \\
\hline
\end{tabular}

Data presented as mean \pm standard error of the mean from 3 independent samples $(n=3)$.

${ }^{\mathrm{ab}}$ Values within the same column not sharing the same superscript are different $(\mathrm{p}<0.05)$ analyzed using Tukey's HSD post hoc test.

${ }^{\mathrm{XY}}$ Values within the same row and within the same storage temperature not sharing the same superscript are different $(\mathrm{p}<0.05)$ analyzed using Tukey's HSD post hoc test.

shown to be optimal at 0.1 to 0.2 aw (Champagne et al., 1996). In the current study, the slightly higher water activity of the dried cultures may have largely affected the viability of the $L$. plantarum cells during storage. Previous studies indicated that lipid oxidation of the membrane fatty acid was predominantly responsible for cell death during storage (Teixeira et al., 1996; Kurtmann et al., 2009). Thus, decreasing water activity and oxygen in the packaging have shown to stabilize freeze-dried cultures (Kurtmann et al., 2009). In addition, the temperature can also influence the rate and magnitude of lipid oxidation. Current work observed higher mortality in $L$. plantarum population during storage at ambient temperature. A number of studies have shown that storage of freeze-dried cultures at higher temperatures resulted in a higher loss in viability a shorter shelf life. For instance, storage of vacuumpackaged freeze-dried $P$. aglomerans stored at $4{ }^{\circ} \mathrm{C}$ for $90 \mathrm{~d}$ showed no more than $0.5 \mathrm{log}$ viability loss, while those that were stored at $25^{\circ} \mathrm{C}$ resulted in $3 \log$ decrease in viability after $28 \mathrm{~d}$ (Costa et al., 2002). Moreover, previous work of Champagne et al. (1996) showed that viability loss of a freeze-dried culture containing Bifidobacrium longum at $20^{\circ} \mathrm{C}$ were $100 \mathrm{x}$ greater than those that were stored at $4^{\circ} \mathrm{C}$. Similar observation was reported by Dhewa et al. (2014) where a considerable reduction in viability of $L$. plantarum was observed in freeze-dried symbiotic formulation stored at $25^{\circ} \mathrm{C}$ for 90 d while those that were stored at $4^{\circ} \mathrm{C}$ exhibit higher $L$. plantarum survival. Selmer-Olsen et al. (1999) recommended $0-5^{\circ} \mathrm{C}$ storage temperature for freeze-dried cultures because low temperatures maintain lower metabolic rate, thus increases storage stability.

\subsection{Fermentation characteristics of freeze-dried Lactobacillus plantarum $S 20$}

Changes in lactic acid bacteria (LAB) population, $\mathrm{pH}$, and total soluble sugar (TSS) of mung bean slurry during $32 \mathrm{hrs}$ of aerobic fermentation at $37^{\circ} \mathrm{C}$ are presented in Figure 3. Results show that LAB population changes in mung bean slurry with fresh and freeze-dried starter culture showed a similar trend (Figure 3A). It appears that LAB in both treatments entered exponential growth phase any time between 0 and $4^{\text {th }} \mathrm{hr}$ of fermentation due to the added $L$. plantarum S20 inoculum. Exponential growth phase for mung bean slurry with freeze-dried L. plantarum S20 extended up to $8 \mathrm{hrs}$ of fermentation where about $2.0 \log$ cycle increases in $\mathrm{LAB}$ population was observed, from an initial $\mathrm{LAB}$ population of approx. $7.0 \log (\mathrm{CFU} / \mathrm{mL})$ to $9.30 \log$ $(\mathrm{CFU} / \mathrm{mL})$. It is evident that the maximum LAB population in mung bean with freeze-dried culture was reached faster compared to mung bean slurry with fresh culture. The LAB population in mung bean slurry with freeze-dried culture peaked after 8 hrs with cell population of $9.30 \log (\mathrm{CFU} / \mathrm{mL})$, while $\mathrm{LAB}$ in mung bean with fresh culture of $L$. plantarum S20 peaked after 16 and $18 \mathrm{hrs}$ with cell population 9.07 and $9.12 \mathrm{log}$ $(\mathrm{CFU} / \mathrm{g})$. The significant increases in LAB population in both treatments caused a significant drop in mung bean slurry $\mathrm{pH}$ and TSS. Highest $\mathrm{pH}$ drop (from $\mathrm{pH} 6.78$ to $\mathrm{pH}$ 3.82) was observed after $8 \mathrm{hrs}$ of fermentation in mung bean slurry inoculated with freeze-dried starter, while $\mathrm{pH}$ drop in treatment with fresh starter culture was slower from $\mathrm{pH} 6.81$ to $\mathrm{pH} 3.72$, which extended up to 16 and 24 hrs. It is observed that TSS in mung bean slurry with either fresh or freeze-dried L. plantarum S20 starter decreased $(p<0.05)$ exponentially over time from 0 to $16 \mathrm{hrs}$ and leveled off until the end of fermentation (Figure 3C).

Higher $(p<0.05)$ drop in TSS was observed in mung bean slurry with a freeze-dried starter. The LAB growth curve trend corresponding to $\mathrm{pH}$ and TSS drop in mung bean slurry with $L$. plantarum S20 indicates sugar utilization of L. plantarum inoculum added in the mung bean slurry. This trend was not observed in the control where natural fermentation was used. The LAB population present in the natural microflora of mung bean was only observed after 4 hrs of fermentation and exponential growth phase was extended up to $16 \mathrm{hrs}$ where the maximum population of $7.15 \log (\mathrm{CFU} / \mathrm{mL})$ was reached. This population level is significantly lower than the maximum population achieved by mung bean slurry with $L$. plantarum S20. This trend also 
(A)

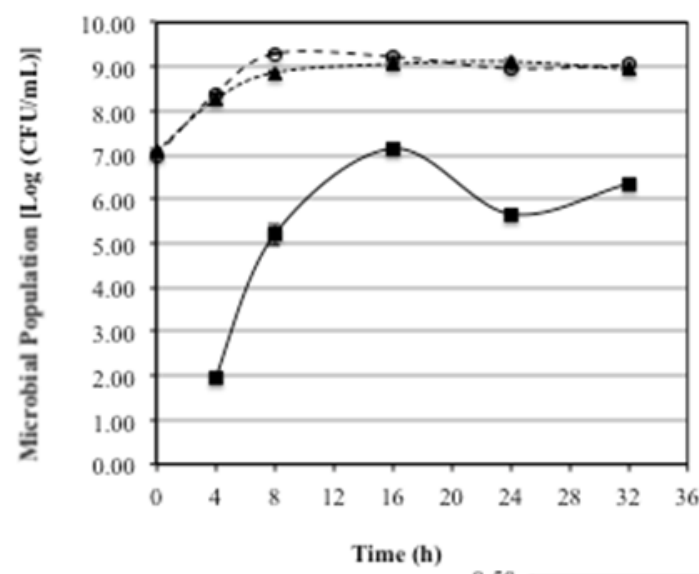

(B)

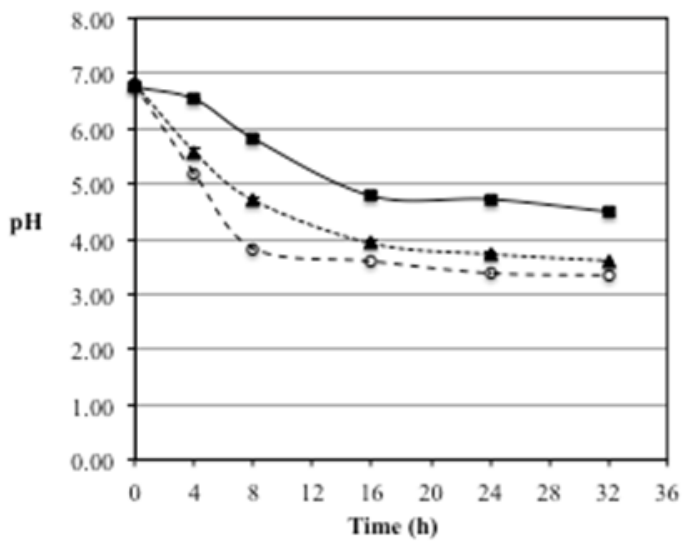

(C)

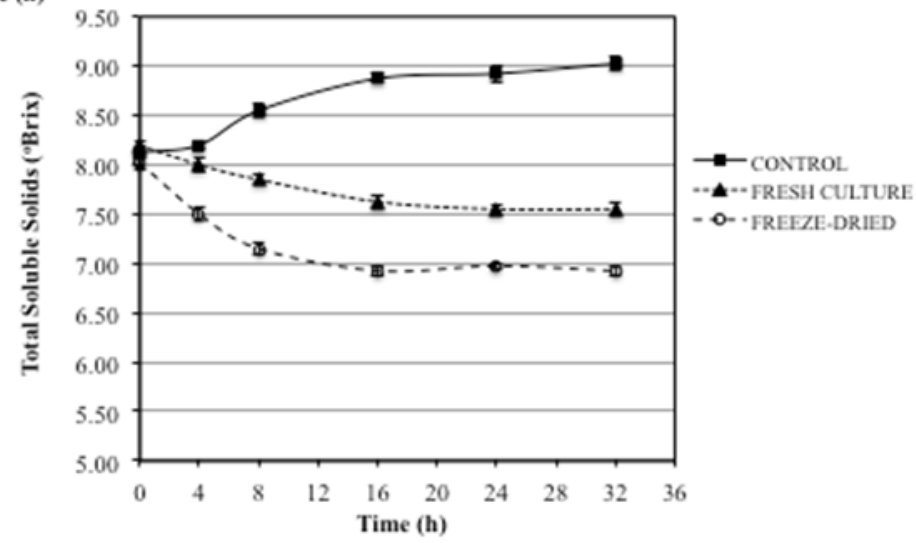

Figure 3. Changes in lactic acid bacteria population (A), $\mathrm{pH}$ (B), and total soluble sugars (TSS) (C) during 32 hrs mung bean slurry fermentation at $37^{\circ} \mathrm{C}$ with lyophilized culture, fresh, and without culture. Data presented as means from 4 independent samples. Error bars represent standard error of the mean $(n=4)$.

corresponds to higher minimum $\mathrm{pH}$ achieved by mung bean slurry without starter culture as compared to mung bean inoculated with fresh or freeze-dried $L$. plantarum S20 starter. Interestingly, unlike the other treatments, TSS gradually increased in mung bean slurry without a starter culture. This can be attributed to biological activities by some LAB species naturally present in mung bean that survived pasteurization. For instance, heat-resistant, spore-forming, and lactic acid-producing Bacillus spp. (e.g., Bacillus subtilis) was reported to be the most predominant fermenting species in soybean and mung bean (Shrestha et al., 2013; John and Olusegun, 2016). Bacillus species can produce a variety of enzymes capable of hydrolyzing macromolecules like starch into soluble sugars like oligosaccharides and simple sugars (Neway, 1989; Shrestha et al., 2013), and this may have contributed to the increasing trend in TSS observed in the current study. This additional step could have slowed down the conversion of soluble sugars (sucrose, glucose, etc.) into lactic acid, hence resulted in a much slower $\mathrm{pH}$ drop.

Previous work by Wu et al. (2015) on L. plantarum fermentation of mung bean milk showed slightly different results due to different mung bean preparation, sucrose concentration, and $L$. plantarum strain used. They reported that $L$. plantarum B1-6 fermentation mung bean beverage (without okara) supplemented with 5.55\% sucrose and 5.19\% inoculum concentration reached optimum acidity and highest LAB population of $8.96 \mathrm{log}$ $(\mathrm{CFU} / \mathrm{mL})$ after $4.86 \mathrm{~h}$ of fermentation at $35.4^{\circ} \mathrm{C}$.

Previous studies have demonstrated that mung bean could be used as a fermentation substrate for $L$. plantarum. L. plantarum has been found to dominate early stages of a 4-stage of fermentation of mung bean as a base material for lu-doh-huang (Taiwanese herbal medicine) (Chao et al., 2013). In addition, a number of studies have documented the use of $L$. plantarum as a starter culture for mung bean-based fermentations (Wu et al., 2015; Landete et al., 2015; Gan et al., 2017; Świeca et al., 2018). Current work showed that the use of freezedried L. plantarum S20 starter was able to rapidly decrease $\mathrm{pH}$ of fermenting mung bean below $\mathrm{pH} 4.0$ corresponding to maximum population of $9.3 \log$ after 8 hrs. This indicates that freeze-dried L. plantarum S20 has successfully started the fermentation process. Previous studies documented the ability of rapid acidification of freeze-dried $L$. plantarum starter for cassava fermentation has been previously documented (Yao et al., 2009). An important characteristic of potential starter strains is their ability to acidify their environment rapidly, which could inhibit the growth of contaminating spoilage and pathogenic microorganisms (Smulders et al., 1986). Leroy and De Vuyst (2004) reported that the direct addition of selected starter culture to raw materials 
resulted in dominance by the best-adapted strains. Furthermore, it is worth noting that freeze-dried $L$. plantarum S20 starter culture developed in the current study showed faster substrate acidification and LAB growth compared to MRS-grown living cells. This finding was inconsistent to previous reports, which showed that freeze-drying could impair metabolic activities of microorganisms upon rehydration (Meng et al., 2008; Mahidsanan et al., 2017) and could decrease growth and acidification activity (Fonseca et al., 2000; Santivarangkna et al., 2007). In the current study, sublethal stress due to freezing and freeze-drying process may have a role in rapid acidification and growth observed when freeze-dried L. plantarum S20 culture was used to ferment mung bean slurry. Previous work on the pre-inoculation treatment of Lactobacillus sakei starter culture with sublethal stress (cold shock, heat shock, salt shock) resulted in increased growth and acid production during sausage fermentation (Hüfner and Hertel, 2008). However, the extent of damage to microbial cells exerted by sublethal stresses applied to $L$. sakei is not as damaging compared to freeze-drying. Since current work has limited scope, current findings on this area warrant further study.

\section{Conclusion}

Results of the current study were able to demonstrate that mung bean powder formulated with either trehalose or sucrose could be used as a freeze-drying medium for L. plantarum S20. Results indicate that drying medium formulation and storage temperature greatly affected $L$. plantarum S20 viability during freeze-drying and subsequent storage. Supplementing of mung bean powder with any of the two disaccharides at $5 \%(\mathrm{w} / \mathrm{v})$ has improved tolerance of $L$. plantarum S20 to freezedrying. In addition, no difference was observed between sucrose and trehalose in terms of their cryoprotective ability on $L$. plantarum S20 during freeze-drying and subsequent storage. Low temperature storage at $6 \pm 2^{\circ} \mathrm{C}$ performed better than ambient storage $\left(30 \pm 1^{\circ} \mathrm{C}\right)$ in minimizing viability loss of L. plantarum S20. However, drying medium formulations used in the study was not able to maintain the stability of $L$. plantarum S20 throughout storage. A significant decline of 2.0 to $>4.0$ $\log (\mathrm{CFU} / \mathrm{g})$ in $L$. plantarum $\mathrm{S} 20$ population was observed in all drying medium treatments during cold and ambient storage. In future research, it will be useful to optimize the formulation of freeze-drying medium preparations, packaging conditions, and freeze-drying parameters to achieve higher recovery and stability for $L$. plantarum S20. In addition to mung powder and disaccharides, the incorporation of additives must be considered to further improve the shelf stability of freeze -dried culture. When freeze-dried L. plantarum S20 was used as a starter culture in mung bean slurry, it was able to acidify the slurry from $\mathrm{pH} 6.8$ to $\mathrm{pH} 3.8$ after $8 \mathrm{hrs}$ with maximum LAB population of $9.2 \log (\mathrm{CFU} / \mathrm{mL})$. Acidification of mung bean slurry by fresh culture (nonfreeze-dried) on the other hand appeared to be slower than the freeze-dried culture. This observation contradicts previous findings. While freeze-dried $L$. plantarum S20 culture developed in the current study could be used as a starter culture for mung bean-based fermentations, its ability to perform better than nonfreeze-dried culture by rapidly growing and acidifying mung bean slurry warrant further research.

\section{Conflict of Interest}

Authors declare no conflict of interest.

\section{Acknowledgments}

The University of the Philippines Los Baños Office of the Vice-Chancellor for Research and Extension funded this study. Special thanks to Dr. Francisco Elegado of the UPLB National Institute of Molecular Biology and Biotechnology for providing us with pure $L$. plantarum S20 culture obtained from their previous research.

\section{References}

Anwar, F., Latif, S., Przybylski, R., Sultana, B. and Ashraf, M. (2007). Chemical composition and antioxidant activity of seeds of dif-ferent cultivars of mung bean. Journal of Food Science, 72(7), S503S510.

3841.2007.00462.x

Allison, S.D., Chtang, B., Randolph, T.W. and Carpenter, J.F. (1999). Hydrogen bonding between sugar and protein is responsible for inhibition of dehydration-induced protein unfolding. Archives of Biochemistry and Physics, 365(2), 289-298. https:// doi.org/10.1006/abbi.1999.1175

BAFS [Bureau of Agriculture and Fisheries Product and Standards]. (2012). Philippine National Standard: Mungbeans - classification and grading. PNS/ BAFPS 105:2012. ICS 67.080.01. Phillipines: BAFS.

Carvalho, A.S., Silva, J., Ho, P., Teixeira, P., Malcata, F.X. and Gibbs, P. (2003a). Effect of various growth media upon survival during storage of freeze-dried Enterococcus faecalis and Enterococcus durans. Journal of Applied Microbiology, 94(6), 947-952. https://doi.org/10.1046/j.1365-2672.2003.01853.x

Carvalho, A.S., Silva, J., Ho, P., Teixeira, P., Malcata, F.X. and Gibbs, P. (2003b). Effect of different sugars added to the growth and drying medium upon 
thermotolerance and survival during storage of freeze-dried Lactobacillus delbrueckii ssp. bulgaricus. Biotechnology Progress, 20(1), 248-254. https://doi.org/10.1021/bp034165y

Carvalho, A.S., Silva, J., Ho, P., Teixeira, P., Malcata, F.X. and Gibbs, P. (2002). Effect of additives on survival of freeze-dried Lactobacillus plantarum and Lactobacillus rhamnosus during storage. Biotechnology Letters, 24, 1587-1591. https:// doi.org/10.1023/A:1020301614728

Carvalho, A.S., Silva, J., Ho, P., Teixeira, P., Malcata, F.X. and Gibbs, P. (2004). Relevant factors for the preparation of freeze-dried lactic acid bacteria. International Dairy Journal, 14(10), 835-847. https://doi.org/10.1016/j.idairyj.2004.02.001

Castro, H.P., Teixeira, P.M. and Kirby, R. (1997). Evidence of membrane damage in Lactobacillus bulgaricus following freeze-drying. Journal of Applied Microbiology, 82(1), 87-94. https:// doi.org/10.1111/j.1365-2672.1997.tb03301.x

Champagne, C.P., Mondou, F., Raymond, Y. and Roy, D. (1996). Effect of polymers and storage temperature on the stability of freeze-dried lactic acid bacteria. Food Research International, 29(5-6), 555-562. https://doi.org/10.1016/0963-9969(95) 00050-X

Chao, S.-H., Huang, H.-Y., Chang, C.-H. Yang, C.-H., Cheng, W.-S., Kang, Y.-H., Watanabe, K. and Tsai, Y.-C. (2013). Microbial Diversity Analysis of Fermented Mung Beans (Lu-Doh-Huang) by Using Pyrosequencing and Culture Methods. PLOS ONE, 8, e63816. https://doi.org/10.1371/ journal.pone. 0063816

Chavarri, F.J., De Paz, M. and Nueez, M. (1988). Cryoprotective agents for frozen concentrated starters from non-bitter Streptococcus lactis strains, Biotechnology Letters, 10, 11-16. https:// doi.org/10.1007/BF01030016

Costa, E., Usall, J., Teixido, N., Torres, R. and Vinas, I. (2002). Effect of package and storage conditions on viability and efficacy of the freeze-dried biocontrol agent Pantoea agglomerans strain CPA-2. Journal of Applied Microbiology, 92(5), 873-878. https:// doi.org/10.1046/j.1365-2672.2002.01596.x

Crowe, L.M., Reid, D.S. and J. H. Crowe. (1996). Is trehalose special for preserving dry biomaterials? Biophysical Journal, 71, 2087-2093. https:// doi.org/10.1016/S0006-3495(96)79407-9

De Paz, R.A., Dale, D.A., Barnett, C.C., Carpenter, J.F., Gaertner, A.L. and Radolph, T.W. (2002). Effects of drying methods and additives on the structure, function, and storage stability of subtilisin: role of protein conformation and molecular mobility. Enzyme and Microbial Technology, 31(6), 765-774. https://doi.org/10.1016/S0141-0229(02)00173-4

Dhewa, T., Pant, S. and Mishra, V. (2014). Development of freeze dried synbiotic formulation using a probiotic strain of Lactobacillus plantarum. Journal of Food Science and Technology, 51, 83-89. https:// doi.org/10.1007/s13197-011-0457-2

Durso, L. and Hutkins, R. (2003). Starter cultures. In Caballero, B. (Ed.). Encyclopedia of Food Sciences and Nutrition. $2^{\text {nd }}$ ed., p. 5583-5593. Cambridge, MA: Academic Press. https://doi.org/10.1016/B0-12227055-X/01146-9

Fonseca, F., Beal, C. and Corrieu, G. (2000). Method of quantifying the loss of acidification activity of lactic acid starters during freezing and storage. Journal of Dairy Research, 67(1), 83-90. https:// doi.org/10.1017/S002202999900401X

Gan, R.-Y., Shah, N.P., Wang, M.-F., Lui, W.-Y. and Corke, H. (2017). Lactobacillus plantarum WCFS1 fermentation differentially affects antioxidant capacity and polyphenol content in mung bean (Vigna radiata) and soya Bean (Glycine max) milks. Journal of Food Processing and Preservation, 41(1), 12944. https://doi.org/10.1111/jfpp.12944

Gisela, G., Leonardo, A.E., Lucia, P., Rodrigo, V., Eduard, G. and Angeles, C.M. (2014). Enhancement of the viability of Lactobacillus plantarum during the preservation and storage process based on the response surface methodology. Food and Nutrition Sciences, 5, 1746-1755. https://doi.org/10.4236/ fns. 2014.518188

Hongpattarakere, T., Rattanaubon, P. and Buntin, N. (2012). Improvement of freeze-dried Lactobacillus Plantarum survival using water extracts and crude fibers from food crops. Food and Bioprocess Technology, 6, 1885-1896. https://doi.org/10.1007/ s11947-012-1018-z

Hubálek, Z. (1996). Cryopreservation of microorganisms. Prague, Check Republic: Academia.

Hüfner, E. and C. Hertel. (2008). Improvement of raw sausage fermentation by stress-conditioning of the starter organism Lactobacillus sakei. Current Microbiology, 57, 490-496. https://doi.org/10.1007/ s00284-008-9274-x

Jalali, M., Abedi, D., Varshosaz, J., Najjarzadeh, M., Mirlohi, M. and Tavakoli, N. (2012). Stability evaluation of freeze-dried Lactobacillus paracasei subsp. tolerance and Lactobacillus delbrueckii subsp. bulgaricus in oral capsules. Research in Pharmaceutical Sciences, 7(1), 31-36. 
Jofré, A., Aymerich, T. and Garriga, M. (2015). Impact of different cryoprotectants on the survival of freezedried Lactobacillus rhamnosus and Lactobacillus casei/paracasei during long-term storage. Beneficial Microbes, 6, 381-386. https://doi.org/10.3920/ BM2014.0038

John, K. and Olusegun, O. (2016). Effect of fermentation on the microbial, proximate and mineral composition of mung bean (Vigna radiata). Journal of Applied Life Sciences International, 5(4), 1-12. https:// doi.org/10.9734/JALSI/2016/25298

Kim, S., Lee, B., Baik, M., Joo, M.-H. and Yoo, S.-H. (2007). Chemical structure and physical properties of mung bean starches isolated from 5 domestic cultivars. Journal of Food Science, 72(9), 471-477. https://doi.org/10.1111/j.1750-3841.2007.00525.x

Kurtmann, L., Carlsen, C.U., Risbo, J. and Skibsted, L. H. (2009). Storage stability of freeze-dried Lactobacillus acidophilus (La-5) in relation to water activity and presence of oxygen and ascorbate. Cryobiology, 58(2), 175-180. https:// doi.org/10.1016/j.cryobiol.2008.12.001

Landete, J. M., Hernández, T., Robredo, S., Dueñas, M., de las Rivas, B., Estrella, I. and Muñoz, R. (2015). Effect of soaking and fermentation on content of phenolic compounds of soybean (Glycine max cv. Merit) and mung beans (Vigna radiata [L] Wilczek). International Journal of Food Sciences and Nutrition, 66(2), 203-209. https:// doi.org/10.3109/09637486.2014.986068

Leroy, F. and De Vuyst, L. (2004). Lactic acid bacteria as functional starter cultures for the food fermentation industry. Trends in Food Science and Technology, 15(2), 67-78. https://doi.org/10.1016/ j.tifs.2003.09.004

Leslie, S.B., Israeli, E., Lighthart, B., Crowe, J.H. and Crowe, L.M. (1995). Trehalose and sucrose protect both membranes and proteins in intact bacteria during drying. Applied and Environmental Microbiology, 61, 3592-3597. https:// doi.org/10.1128/AEM.61.10.3592-3597.1995

Li, W.H., Guo, H.M., Wang, P., Tian, X., Zhang, W., Saleh, A.S.M., Zheng, J., Ouyang, S., Luo, Q. and Zhang, G. (2015). Physicochemical characteristics of high pressure gelatinized mung bean starch during recrystallization. Carbohydrates Polymers, 131, 432 -438. https://doi.org/10.1016/j.carbpol.2015.05.076

Mahidsanan, T., Gasaluck, P. and Eumkeb, G. (2017). A novel soybean flour as a cryoprotectant in freezedried Bacillus subtilis SB-MYP-1. LWT-Food Science and Technology, 77, 152-159. https:// doi.org/10.1016/j.lwt.2016.11.015
Mendoza, G.M., Pasteris, S.E, Otero, M.C. and NaderMacías, M.E.F. (2013). Survival and beneficial properties of lactic acid bacteria from raniculture subjected to freeze-drying and storage. Journal of Applied Microbiology, 116(1), 157-166. https:// doi.org/10.1111/jam.12359

Meng, X.C., Stanton, C., Fitzgerald, G.F., Daly, C. and Ross, R.P. (2008) Anhydrobiotics: The challenges of drying probiotic cultures. Food Chemistry, 106(4), 1406-1416. https://doi.org/10.1016/ j.foodchem.2007.04.076

Neway, O. (1989). Fermentation process development of industrial organisms., p. 73-75. New York, USA: Marcel Dekker.

Nguyen, H., Elegado, F., Librojo-Basilio, N., Mabesa, R. and Dizon, E. (2010). Isolation and characterization of selected lactic acid bacteria for improved processing of Nem chua, a traditional fermented meat from Vietnam. Beneficial Microbes, 1, 67-74. https://doi.org/10.3920/BM2009.0001

N'Guessan, F.K., Coulibaly, H.W., Alloue-Boraud, M.W.A., Cot, M. and Dje, K.F. (2016). Production of freeze-dried yeast culture for the brewing of traditional sorghum beer, tchapalo. Food Science and Nutrition, 4(1), 34-41. https://doi.org/10.1002/ fsn3.256

Nualkaekul, S., Deepika, G. and Charalampopoulos, D. (2012). Survival of freeze dried Lactobacillus plantarum in instant fruit powders and reconstituted fruit juices. Food Research International, 48(2), 627 -633. https://doi.org/10.1016/j.foodres.2012.06.003

Okafor, N., Azubike, C. and Ibenegbu, C. (1999). Carriers for starter cultures for the production of garri, a fermented food derived from cassava. World Journal of Microbiology and Biotechnology, 15, 231 -234. https://doi.org/10.1023/A:1008867824975

Paul, E., Sasikumar, P., Gomathi, S., Abhishek, A. and Selvam, G.S. (2017). Recombinant lactic acid bacteria secreting $\mathrm{OxdC}$ as a novel therapeutic tool for the prevention of kidney stone disease. In Grumezescu, A.M. (Ed.). Multifunctional Systems for Combined Delivery, Biosensing and Diagnostics., p. 377-345. USA: Elsevier. https:// doi.org/10.1016/B978-0-323-52725-5.00017-4

Perry, S.F. (1998). Freeze-drying and cryopreservation of bacteria. Molecular Biotechnology, 9, 59-64. https://doi.org/10.1007/BF02752697

Polge, C., Smith, A. U. and Parkes, A.S. (1949). Revival of spermatozoa after vitrification and dehydration at low temperatures. Nature, 164, 666. https:// doi.org/10.1038/164666a0

Ray, R.C. and Joshi, V.K. (2014). Fermented foods: 
Past, present and future scenario. In Ray, R.C. and Didier, M. (Eds.) Microorganisms and fermentation of traditional foods., p.1-36, Boca Raton, Florida, USA: CRC Press. https://doi.org/10.1201/b17307

Rezac, S., Kok, C.R., Heermann, M. and Hutkins, R. (2018). Fermented foods as a dietary source of live organisms. Frontiers in Microbiology, 9, 1785. https://doi.org/10.3389/fmicb.2018.01785

Ricci, A., Allende, A., Bolton, D., Chemaly, M., Davies, R., Girones, R., Koutsoumanis, K., Lindqvist, R., Nørrung, B., Robertson, L., Ru, G., Escamez, P.S.F., Sanaa, M., Simmons, M., Skandamis, P., Snary, E., Speybroeck, N., Kuile, B.T., Threlfall, J., Wahlstrom, H., Cocconcelli, P.S., Peixe, L., Maradona, M.P., Querol, A., Suarez, J.E., Sundh, I., Vlak, J., Correia, S. and Herman, L. (2017). Update of the list of QPS-recommended biological agents intentionally added to food or feed as notified to EFSA 5: suitability of taxonomic units notified to EFSA until September 2016. European Food Safety Authority Journal, 15(7), e04884. https:// doi.org/10.2903/j.efsa.2017.4884

Rompothi, O., Pradipasena, P., Tananuwong, K., Somwangthanaroj, A. and Janjarasskul, T. (2017). Development of non-water soluble, ductile mung bean starch based edible film with oxygen barrier and heat sealability. Carbohydrates Polymers, 157, 748-756.

j.carbpol.2016.09.007

Santivarangkna, C., Kulozik, U. and Foerst, P. (2007). Alternative drying processes for the industrial preservation of lactic acid starter cultures. Biotechnology Progress, 23(2), 302-315. https:// doi.org/10.1021/bp060268f

Savedboworn, W., Kerdwan, N., Sakorn, A., Charoen, R., Tipkanon, S. and Pattayakorn, K. (2017). Role of protective agents on the viability of probiotic Lactobacillus plantarum during freeze drying and subsequent storage. International Food Research Journal, 24(2), 787-794.

Selmer-Olsen, E., Birkeland, S.-E. and Sørhaug, T. (1999). Effect of protective solutes on leakage from and survival of immobilized Lactobacillus subjected to drying, storage and rehydration. Journal of Applied Microbiology, 87(3), 429-437. https:// doi.org/10.1046/j.1365-2672.1999.00839.x

Shrestha, A.K., Dahal, N.R. and Ndungutse, V. (2013). Bacillus fermentation of soybean: a review. Journal of Food Science and Technology Nepal, 6, 1-9. https://doi.org/10.3126/jfstn.v6i0.8252

Smulders, F.J.M., Barendsen, P., van Logtestijn J.G., Mossel, D.A.A. and van Der Marel, G.M. (1986). Lactic acid: consideration in favor of its acceptance as a meat decontaminant. Journal of Food Technology, 21(4), 419-436. https://doi.org/10.1111/ j.1365-2621.1986.tb00420.x

Strasser, S., Neureiter, M., Geppl, M., Braun, R. and Danner, H. (2009). Influence of lyophilization, fluidized bed drying, addition of protectants, and storage on the viability of lactic acid bacteria. Journal of Applied Microbiology, 107(1), 167-177. https://doi.org/10.1111/j.1365-2672.2009.04192.x

Świeca, M., Kordowska-Wiater, M., Pytka, M., GawlikDziki, U., Bochnak, J., Złotek, U. and Baraniak, B. (2018). Lactobacillus plantarum $299 \mathrm{~V}$ improves the microbiological quality of legume sprouts and effectively survives in these carriers during cold storage and in vitro digestion. PLoS OnE 13, e0207793.

https://doi.org/10.1371/ journal.pone.0207793

Teixeira, P., Castro, H. and Kirby, R. (1996). Evidence of membrane lipid oxidation of spray-dried Lactobacillus bulgaricus during storage. Letters in Applied Microbiology, 22(1), 34-38. https:// doi.org/10.1111/j.1472-765X.1996.tb01103.x

Telang, C., Yu, L. and Suryanarayanan, R. (2003). Effective inhibition of mannitol crystallization in frozen solutions by sodium chloride. Pharmaceutical Research, 20, 660-667. https://doi.org/10.1023/ A:1023263203188

Thammavongs, B., Corroler, D., Panoff, J.M., Auffray, Y. and Boutibonnes, P. (1996). Physiological response of Enterococcus faecalis $\mathrm{JH} 2-2$ to cold shock: growth at low temperatures and freezing/ thawing challenge. Letters in Applied Microbiology, 23(6), 398-402. https://doi.org/10.1111/j.1472765X.1996.tb01345.x

Trachoo, N., Panomkorn, W., Moongngarm, A. and Suttajit, M. (2008). Stability of freeze-dried Lactobacillus acidophilus in banana, soybean and pearl barley powders. Journal of Biological Science, $8(1), \quad 119-124 . \quad$ https://doi.org/10.3923/ jbs.2008.119.124

Wu, H., Rui, X., Li, W., Chen, X., Jiang, M. and Dong, M. (2015). Mung bean (Vigna radiata) as probiotic food through fermentation with Lactobacillus plantarum B1-6. LWT - Food Science and Technology, 63(1), 445-451. https://doi.org/10.1016/ j.lwt.2015.03.011

Yao, A.A., Dortu, C., Egounlety, M., Pinto, C., Edward, V.A., Huch, M., Mengu, M. and Thonart, P. (2009). Production of freeze-dried lactic acid bacteria starter culture for cassava fermentation into gari. African Journal of Biotechnology, 8, 4996-5004. 